\title{
Evaluation of the Medical Abortion Kit Dispensing Practices of Community Pharmacies in Kathmandu Valley, Nepal
}

ISSN: 2640-9666

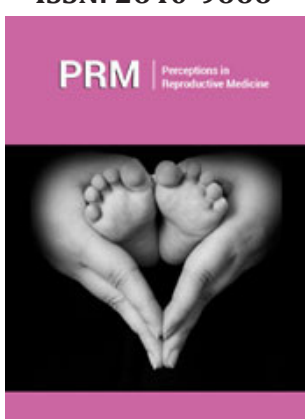

*Corresponding author: Gyawali M, Janamaitri Foundation Institute of Health Sciences (JFIHS), Nepal

Submission: 啙 August 10, 2020

Published: 僵September 04, 2020

Volume 4 - Issue 1

How to cite this article: Gyawali M, Thapa HS, Bhandari P, et al. Evaluation of the Medical Abortion Kit Dispensing Practices of Community Pharmacies in Kathmandu Valley, Nepal. Perception in Reproductive Medicine. 4(1). PRM. 000578. 2020.

DOI: $10.31031 /$ PRM.2020.04.000578

Copyright@ Gyawali M, This article is distributed under the terms of the Creative Commons Attribution 4.0 International License, which permits unrestricted use and redistribution provided that the original author and source are credited.

\author{
Gyawali M1*, Thapa HS², Bhandari ${ }^{1}{ }^{1}$, Dangi NB ${ }^{3}$, Saud $B^{1}$ and Shrestha $\mathrm{RK}^{1}$ \\ ${ }^{1} J a n a m a i t r i$ Foundation Institute of Health Sciences (JFIHS), Nepal \\ ${ }^{2}$ School of Health Science, CTEVT, Nepal \\ ${ }^{3}$ School of Health and Allied Sciences, Nepal
}

\section{Abstract}

The risk of unsafe abortion lies mainly in the developing countries like Nepal. Medical abortion is use of medicines to terminate pregnancy. Mostly invalid pregnant women are ready to afford high cost without proper counseling due to social stigma and fear of family and society which is in scene among various community pharmacies in Nepal. Thus, this study was conducted in Kathmandu valley of Nepal to evaluate medical abortion kit dispensing practices of community pharmacies (CPs). Semi-structured types questionnaire was used as the instrument for data collection. Data collection was done through simulated patient via simple random sampling technique in 102 pharmacies. Out of six brand of medical abortion kit available in Nepalese market, $32 \%$ is unregistered product. It is found that $78 \%$ of the CPs used to sell in higher price than labeled price. Most of the CPs did not ask the general (screening) questions and also most of them counseled only about drug dosing and common side effects and price but neither of CPs referred (suggest to visit) to trained abortion service provider. The study discloses that CPs has been practicing the dispensing of medical abortion kit illegally and no proper screening and counseling was done. CPs are providing only profit oriented services which may be due to lack of skilled human resources in CPs.

Keywords: Evaluation, Medical abortion kit, Community pharmacy, Counseling, Screening

Abbreviations: CPs: Community pharmacies; SP: Simulated patients; MTP: Mifepristone and Misoprostol combination kit; Rs: Nepalese rupees

\section{Introduction}

An abortion is a process to cease pregnancy with the aid of either drug or surgical procedure to remove the embryo or fetus and placenta. According to World Health Organization (WHO), abortion is the cessation of pregnancy before the fetus has attained viability, i.e. become capable of independent extra-uterine life. Medical abortion (MA) is use of medicine to terminate pregnancy. It is also known as "non-surgical abortion" and "medical abortion" [1]. The hazard of unsafe abortion is found more in the developing countries. The rate of unsafe abortion is found highly in African, Latin American and the Caribbean, followed by South and South-East Asian people. Worldwide, it has been expected that some 68,000 women die each year as a result of unsafe abortion, and 5.3 million women suffer with temporary or permanent disability. The public health risk is found highest in the developing countries [1]. In a developing nation like Nepal, where policy and law regarding abortion is liberal but the implementation part is poor that results in the practice of unsafe abortion. Another major problem regarding unsafe abortion is due to lack of technical human resource, poor socio-economic condition as well as difficult geographic condition of the country. The main causes of practicing unsafe abortion in Nepal even after the legalization are- lack of awareness about current new abortion law and difficulty of access of safe abortion services, high cost procedure of abortion, limited number of abortion service centers, poor decision 
making ability of pregnant women and social fear. Abortion is even now considered as wrong deeds in Nepalese community and women usually are in search for clandestine street abortions to ensure confidentiality [2].

Abortion has been legalized, but in order to make abortion services available throughout the countries there is a need for skilled service providers, adequate equipment, and essential drugs. Abortion was legalized in Nepal under the $11^{\text {th }}$ amendment to the Country Code (Muluki Ain) in March 2002 and approved by government of Nepal in September 2002. It empowers women's rights to control over and decide on their unplanned pregnancies [3]. According to the health point of view, abortion is the cessation of pregnancy and is "legal under certain conditions in almost all countries, ninety six percentages of countries recognizing a risk to a mother's life as legal basis for abortion"[4]. Medical abortion or abortion by orally administered regimens of mifepristone and misoprostol has recently been accepted worldwide as an effective and safe option for early abortion [5]. It is proven fact that there is still a need of expanding safe abortion clinics to provide medical abortion services to venerable group of people without doing surgical abortion procedures [6].

Medical abortion has become an alternative process of terminating pregnancy in first trimester by prostaglandins and anti- progesterone. Safe Abortion guidelines states that use of medical abortion drug (mifepristone and misoprostol) up to nine weeks, nine to twelve weeks, and after twelve weeks of gestation. In all three conditions mifepristone $200 \mathrm{mg}$ is followed by misoprostol $1800 \mu \mathrm{g}$ (microgram) is needed to administer either through vaginal or sub sublingual route. Initially mifepristone is taken then after twenty-four to forty-hour misoprostol must be give through above mentioned route. There may be need of misoprostol $400 \mu \mathrm{g}$ dose on the basis of patient conditions. Medical abortion shows ninety five percent success rates [7]. The percentage of pregnant women attending unqualified practitioner for unsafe abortion is also in higher number. Nepalese society still do not accept single mother concept, therefore due to social fear and fear of violation of abortion law, pre-marital pregnancies, illegal pregnancies are subjected to more unsafe abortion. Mostly invalid pregnant women are ready to afford high cost due to social stigma and fear of family and society. In order to maintain prestige the pregnant women take medicine secretly. For this reason, the dispenser are cheating the customer in the price by charging up to five thousand to a medicine which cost three hundred only [8]. The selling of the medical abortion kit without providing adequate information has been widely practiced in the community pharmacies.

\section{Material and Methods}

\section{Research design}

In this study design, general medication order procedure was concurrently used with pharmacists/Assistant pharmacist/
Person involved in dispensing of drug in community pharmacies of different area of Kathmandu valley.

\section{Research setting and population}

The study was conducted in community pharmacies of certain areas of Kathmandu valley. Student of Bachelor of Pharmacy fourth year acted as simulated patient and ask for medical abortion kit along with the information about the Mifepristone and Misoprostol combination (MTP) kit. The information obtained from the dispensers was recorded immediately in the data collection sheet without acknowledging them.

\section{Sample size}

Simple Random sampling technique was used to collect the samples. Sample size for the study was based on 112 community pharmacies, among them 10 Pharmacies had not dispensed MTP Kit and thus sample size for the study was 102 community pharmacies during the period of six months from March to August 2014.

\section{Instrumentation}

The data was collected with self-made semi-structured types questionnaire. The questionnaire was asked being as simulated patient. The scoring for Knowledge and Counseling was done as follows: $50 \%$ of responses considered as low level, (50\%-75\%) considered as moderate and remaining $25 \%$ considered as high level. Simulated patients (SP) visited to community pharmacies alone or sometimes with someone. SP have to observe six things about the kit (manufacturing company, brand name, registered/ unregistered, mentioned price by manufacturing company, expiry date).SP`s had collected Mistol+Pregno, Pregout Kit, MTP-KIT, Mariprist, Mensovit forte kit and Medabon medicines of different brands most commonly found inside the Kathmandu Valley. Also, community pharmacy practitioners were also asked some more information like drug dose, route of administration, direction of use, price, and side effects and so on. Being a simple pregnant lady without letting they know researcher as a pharmacy student. The information was recorded on data collection sheet immediately without acknowledging them. The different brand kits information was kept confidential and coded with A, B, C, D, E and F. All the data were entered and analyzed by using Statistical Package for the Social Sciences (SPSS) version 16.0 and interpreted according to frequency distribution and percentage table.

\section{Result}

The findings of this study included availability of different brands names, availability of registered and unregistered brands, cost variation among same brands and different brands, screening performed by CPs and their counseling practices. The study was conducted in total of $102 \mathrm{CPs}$ in which $70 \%$ of the people involved in dispensing of medicine were male. A total of 6 brands of the medical abortion pills by 6 manufacturing companies were found. Among these $68 \%$ of the brands were found to have registered 
and $32 \%$ were unregistered. From the data it has been found that abortion kit of different brands with minimum of Rs. 400 (C brand kit) and Maximum of Rs. 1104 (B brand kit) were available in market. A brand kit with the marked price of Rs. 825 was found to have been sold on minimum of Rs.800, maximum of Rs.1000 and mean selling price was found to be Rs.887.50. B brand kit with the marked price of Rs.1104 was found to have been sold on minimum of Rs.1000, maximum of Rs. 2000 and mean selling price was found to be Rs.1412.50. C brand kit with the marked price of Rs.400 was found to have been sold on minimum of Rs.400, maximum of Rs.
2000 and mean selling price was found to be Rs.1177.78. Similarly, D brand kit with the marked price of Rs.550 was found to have been sold on minimum of Rs.500, maximum of Rs. 1800 and mean selling price was found to be Rs.1100. E brand kit with the marked price of Rs.875 was found to have been sold on minimum of Rs.825, maximum of Rs. 1800 and mean selling price was found to be Rs.1278.13. F brand with the marked price of Rs.426 was found to have been sold on minimum of Rs.500, maximum of Rs. 1000 and mean selling price was found to be Rs.725, as shown in Table 1.

Table 1: Availability of various brands of medical abortion pills and cost variation.

\begin{tabular}{|c|c|c|c|c|c|c|c|c|}
\hline \multirow{2}{*}{ Brands } & \multirow{2}{*}{ Frequency (\%) } & Market Price (MP) & \multicolumn{3}{|c|}{ Selling Price (SP) } & \multicolumn{3}{c|}{ Percentage } \\
\cline { 3 - 9 } & & Maximum & Maximum & Mean & Minimum & Maximum & Mean & Minimum \\
\hline A & $16(15.6 \%)$ & 825 & 1000 & 887.5 & 800 & 3.03 & -7.58 & -21.21 \\
\hline B & $16(15.6 \%)$ & 1104 & 2000 & 1412.5 & 1000 & 9.42 & -27.94 & -81.16 \\
\hline C & $19(18.6 \%)$ & 400 & 2000 & 1177.78 & 400 & 0 & -194.4 & -400 \\
\hline D & $27(26.4 \%)$ & 550 & 1800 & 1100 & 500 & 9.09 & -100 & -227.27 \\
\hline E & $16(15.6 \%)$ & 875 & 1800 & 1278.13 & 825 & 5.71 & -46.07 & -105.71 \\
\hline F & $8(7.8 \%)$ & 426 & 1000 & 725 & 500 & -17.37 & -70.19 & -134.74 \\
\hline
\end{tabular}

Note: One Nepalese Rupees equals to 0.0084 US Dollar.

The percentage in cost variation were calculated putting formula i.e. (MP-SP)/MP*100. Where the result in '-' indicate higher price than marked price and ' + ' indicate discount on marked price. On average, $7.58 \%$ of the A brand kit was found to have been sold on higher than marked price while $3.03 \%$ was found to have been sold giving discount, B brand kit was sold on $27.94 \%$ higher than marked price while $9.42 \%$ was sold giving discount, $\mathrm{C}$ brand kit was found to have been sold on $194.44 \%$ higher than the marked price, D brand kit was sold on $100 \%$ higher price while $9.09 \%$ was sold on giving discount, $\mathrm{E}$ brand kit was sold on $46.07 \%$ higher price while $5.71 \%$ was sold giving discount and $134.74 \%$ of the $\mathrm{F}$ brand kit was sold on maximum of higher price while $17.37 \%$ was sold on minimum of higher price of which has average higher price as $70.19 \%$. Regarding Distribution of price according to selling of abortion kit $78.0 \%$ of the pharmacies had sold the medical abortion kit in higher price, $12 \%$ of the pharmacies had given discount and only $10.0 \%$ were sold on same price as marked.

Possible question asked by dispenser before dispensing. The result shows that $100 \%$ of CPs asked gestation period, $94 \%$ asked on confirmation of pregnancy, $60 \%$ asked on age, $16 \%$ of the CPs asked frequency of the use medical abortion, $8 \%$ asked if permission was granted from family/discussed with family for abortion and marital status and only $6 \%$ asked about the number of baby. Counseling by the CPs during dispensing of the medications are shown in Table 2. The level of counseling pattern was found that $78 \%$ of the CPs had poor level of counseling, 18\% had moderate and only $4 \%$ had excellent level of counseling pattern. Regarding the knowledge of the CPs in dispensing practices, $86 \%$ of the CPs was found to have low level of knowledge and only $14 \%$ had moderate level of knowledge.

Table 2: Counseling during dispensing in Community pharmacies.

\begin{tabular}{|c|c|c|}
\hline Counseling During Dispensing & Frequency & Percent \\
\hline Direction of use/route of administration & 99 & 92.0 \\
\hline Frequency and duration of use & 90.0 & 58 \\
\hline Possible side effects & 54.0 & 54.0 \\
\hline Drug dose & 40.0 & 34.0 \\
\hline Follow up & 35 & 32 \\
\hline Precaution & 19 & 32.0 \\
\hline
\end{tabular}




\begin{tabular}{|c|c|c|}
\hline Contraindication & 12 & 12.0 \\
\hline Other medication & 6 & 6.0 \\
\hline Special direction & 6 & 6.0 \\
\hline Family planning/contraception use & 4 & 4.0 \\
\hline Interaction & 2 & 2.0 \\
\hline
\end{tabular}

\section{Discussion}

A survey among factory labor in Nepal has shown that sexual activity between unmarried young male and female with nonregular partner was more in practice. One out of five unmarried male and one out of eight unmarried female teenagers were sexually active [9]. Thirty three percent of pregnancies are unplanned, among currently married women of reproductive age in Nepal [10]. In neighboring India, where abortion is legal, the total abortion rate was estimated to be 0.06 in 1978 [11]. In America. The percentages of abortion service centers are lowered by twenty percent tin Hospital based service provider and in rural area since 1982 [12,13]. Methotrexate with Misoprostol was used for medical abortion in early pregnancies in the mid-1990s.And more recently mifepristone has been used for non-surgical abortion [14]. Mifepristone is approved for such use in most of Europe [15] and has been used for more than a decade in France, Sweden and Great Britain [16,17]. Before the US Food and Drug Administration (FDA) approved drug for use as a medical abortifacient in 2000 , it was used in clinical trials in US [18].

In earlier day in Nepal, more emphasis was given on spreading information regarding legal changes to law enforcement authorities, to aware everyone that women should no longer be imprisoned on abortion charges $[19,20]$. Non-government Organization has been carrying out local level awareness about abortion law, policies, by using different types of media. In this studies total of six brands of the medical abortion pills of six manufacturing companies were taken and data was collected with self-made structured questionnaire. The questionnaire was asked being as simulated patient and data was collects in the different heading like availability, registration of brands, and cost variation of brands, price distribution, and possible question asked during dispensing. The findings of study are discussed in the result section.

\section{Conclusion}

Total of 112 community pharmacies were selected among them 10 community pharmacy were not involved in dispensing of medical abortion kit. In remaining 102 community pharmacies, 32\% were from unregistered brands which were found during study period. $78 \%$ of the CPs had sold the medications in higher price than labeled for marked price. Most of the CPs did not ask the general (screening) questions and most of them counseled only about drug dosing, common side effects and price. These dispensing practices may affect the occurrence of negative therapeutic outcomes such as serious adverse effects and other abortion complications (abortion failure). Therefore, there must be strict legal provision for use of medical abortion kit as well as there is need to improve medical abortion kit dispensing practice. Community pharmacies, where women come to claim for the help must refer the woman to trained abortion service provider or send them to well-equipped health care institution run under national protocol for abortion. If it is not possible to refer, counseling should be given to the patient about medication (Abortion kit), its price with necessary advice to save lives.

\section{Limitation}

Study was conducted in certain areas of the Kathmandu valley and may not be the representative of whole nation. Study time was limited and so sample size could not be extended. Thus, finding of study could not be generalized.

\section{References}

1. World Health Organization (2012) Safe abortion: Technical and policy guidance for health systems. WHO, Geneva, Switzerland.

2. Rijal A (2012) A study on: Status of abortion law in Nepal [Masters' Thesis]. Nepal law campus, Tribhuvan University, Kathmandu, Nepal.

3. (1997) Ministry of law, justice and parliamentary affairs. New recommendation on Muluki Ain(National Civil Code) $11^{\text {th }}$ amendment 2002, Kathmandu, Nepal.

4. Williamson JB, Boehmer U (1997) Female life expectancy, gender stratification, health status, and level of economic development: A crossnational study of less developed countries. Soc Sci Med 5(2): 305-317.

5. Santhya K, Verma S (2004) Induced abortion: The current scenario in India. Regional Health Forum.

6. Spiegel BM, Talley J, Shekelle P, Agarwal N, Snyder B, et al. (2011) Development and validation of a novel patient educational booklet to enhance colonoscopy preparation. Am J Gastroenterol 106(5): 875-883.

7. Tang J, Kapp N, Dragoman M, De Souza JP (2013) WHO recommendations for misoprostol use for obstetric and gynecologic indications. Int J Gynaecol Obstet 121(2): 186-189.

8. Nepali P, Ghanashyam k, Aryal M (2014) Increasing unsafe abortion. Kantipur Nepali National Daily 29: 1-2.

9. Puri M (2002) Sexual risk behaviour and risk perception of unwanted pregnancies and sexually transmitted diseases among young factory workers in Nepal. CREHPA, Kathmandu, Nepal.

10. National safe abortion policy, 2003. Ministry of Health, Department of health services family health division 2002 .

11. Tietze C (1981) Induced abortion: A world review.

12. Henshaw SK (1995) Factors hindering access to abortion services. Fam Plann Perspect 27(2): 54-87. 
13. Henshaw SK, Van Vort J (1990) Abortion services in the United States. 1987 and 1988. Fam Plann Perspect 22(3): 102-142.

14. Edward J, Creinin MD (1997) Early abortion. Current problems in obstetrics, gynecology and fertility 20(1): 6-32.

15. Silvestre L, Dubois C, Renault M, Rezvani Y, Baulieu EE, et al. (1990) Voluntary interruption of pregnancy with mifepristone (RU 486) and a prostaglandin analogue: a large-scale French experience. N Engl J Med 322(10): 645-648.

16. Jones RK, Henshaw SK (2002) Mifepristone for early medical abortion: experiences in France, Great Britain and Sweden. Perspect Sex Reprod Health 34(3): 154-161.
17. Trial UM (1990) The efficacy and tolerance of mifepristone and prostaglandin in first trimester termination of pregnancy. Br J Obstet Gynaecol 97(6): 480-486.

18. Bartlett LA, Berg CJ, Shulman HB, Zane SB, Green CA, et al. (2004) Risk factors for legal induced abortion-related mortality in the United States. Obstet Gynecol 103(4): 729-737.

19. (2003) Forum for women, law and development, center for reproductive rights, Ipas. According to the findings of the district prison visit by FWLD, CRLP and Ipas.

20. DBN (2014) Sale and distribution of medicines use for medical abortion 25(2): 28. 